\title{
AC 2010-882: ESTABLISHING ENTREPRENEURIAL OPPORTUNITIES FOR THE DEVELOPING WORLD USING ENGINEERING DESIGN
}

Kevin McGarvey, Rowan University

Michael Panko, Rowan University

Beena Sukumaran, Rowan University

Michael Kerbaugh, Rowan University

Gabriel Posluszny, Rowan University

Anthony Cavalier, Rowan University 


\title{
Establishing Entrepreneurial Opportunities for Developing Countries using Engineering Design
}

\begin{abstract}
This paper describes a program titled "Engineering Innovators without Borders" (EIWB), which works in close collaboration with Engineers without Borders (EWB). The main mission of EIWB is to redesign and develop devices that have market potential and will improve the quality of life in developing countries, while providing entrepreneurial opportunities. In addition, these devices have to be economically and socially sustainable and produced using locally available materials. This has been done utilizing multidisciplinary engineering student teams and has been successfully implemented through the curricular avenue of Junior and Senior Engineering Clinics at Rowan University. The engineering students perform a survey of local communities in developing countries, identified as having a need for engineering skills by Engineers without Borders. During this initial survey, the students identify local entrepreneurial opportunities that require redesign or development of a device that will enhance the quality of life of the local area. The students then work on modifying or designing the device using local materials and input from the local community. Some examples of projects undertaken include development of a human powered grain crusher and a tree climber. The grain crusher being designed at Rowan University has undergone many revisions to make it more affordable and sustainable based on pilot studies and end-user feedback. It can be powered easily by a single person and therefore can utilize human energy for crushing grains efficiently. The second project currently in progress is a palm tree climber. The tree climber will provide a safer alternative to the traditional climbing method used in coconut harvesting, which is to climb with little or no safety equipment or aids. The tree climber has been designed to attach quickly and easily to the tree without damaging the trunk. Both these devices are being developed to be locally produced inexpensively from readily available materials. The students gain a valuable perspective on designing engineering products for developing countries including cultural and economic considerations, sustainability, material and resource availability.
\end{abstract}

\section{Introduction}

"Engineering Innovators without Borders" has been a project at Rowan University since the Fall of 2006. The project began as a means to develop new entrepreneurial opportunities to individuals and businesses in developing countries. Rowan University is a strong proponent of experiential learning, a "bottom-up" method in which general lessons and principles are learned through direct personal experiences and observations. Active modes of learning can enrich, broaden and deepen the knowledge base, which is gained from readings and class lectures ${ }^{1,2,3}$. The system used at Rowan is called Engineering Clinics. This is an eight semester project based series of courses which are a requirement of all engineering students for graduation. It can be seen in the following sections that experiential learning is a hallmark of Rowan's engineering curriculum, which will be utilized for these projects. Professionalism and "Real-Life" engineering practices are emphasized in a multidisciplinary environment, similar to the environment that may be encountered by many engineering students after graduation. The layout of the Engineering Clinic program can be seen in Table 1. 
Table 1

Overview of general technical topics in the eight-semester engineering clinic sequence

\begin{tabular}{l|ll}
\hline Year & $\begin{array}{l}\text { Engineering Clinic Theme } \\
(\text { Fall })\end{array}$ & $\begin{array}{l}\text { Engineering Clinic Theme } \\
\text { (Spring) }\end{array}$ \\
\hline First Year & Engineering Measurements & $\begin{array}{l}\text { Competitive Assessment } \\
\text { Laboratory } \\
\text { Sophomore }\end{array}$ \\
& Multidisciplinary Design & $\begin{array}{l}\text { 16-Week Multidisciplinary } \\
\text { Design Project }\end{array}$ \\
& Modules & \\
Junior & Product Development & Process Development \\
Senior & Multidisciplinary Capstone & Multidisciplinary Capstone \\
& Design/Research Project & Design/Research Project \\
\hline
\end{tabular}

Freshman Clinic is a two-semester long course that introduces freshman to engineering at Rowan University. In Freshman Clinic, the students are introduced to a hands-on, active learning environment through a 3-hour weekly lab and a 1-hour weekly class meeting schedule. The first semester of the course focuses on multidisciplinary engineering experiments using engineering measurements as a common thread. The second semester focuses on the reverse engineering of a commercial product or process. Sophomore Clinic I combines a 1-credit multidisciplinary engineering laboratory with a 3-credit college composition and rhetoric requirement and is cotaught by engineering, composition, and rhetoric faculty. The 3-hour laboratory for the course is a semester-long multidisciplinary design project, with an emphasis on parametric design. Sophomore Clinic II follows the same structure as Sophomore Clinic I, with public speaking taking the place of the composition portion as the 3 credits of required technical communications ${ }^{4,5,6}$. Students enrolled in the Junior/Senior Engineering Clinic work in teams to carry out independent, open-ended research projects. The Junior/Senior Engineering Clinic, a 4semester required course, is an integral part of the engineering curriculum in which students apply engineering principles to emerging technologies. Students work on service related projects or research grants funded by industry or government in multidisciplinary teams. The disciplinary makeup of the teams is driven by the requirements of the project. Teams of students are organized based on their particular skills, interests and backgrounds, then matched to a particular project. The service related projects offered through the junior and senior clinics are not meant to be a volunteer extracurricular activity. The projects usually have regional, national or international impact. "Engineering Innovators without Borders" was introduced through Junior/Senior Engineering Clinics. The first project, the human powered grain crusher, was introduced in the Fall of 2006 through the Engineering Clinic program at Rowan University. After the initial success of the human powered grain crusher, the second project, a coconut tree climber, was started in the Fall of 2009.

\section{The Human Powered Grain Crusher}

\section{Motivation}

In order to find an appropriate technology that could be used in developing countries, the needs of the people in the area where the device would be used had to be studied. Based on an initial survey of a rural community in Senegal, where an EWB project was in progress, one of the most 
pressing needs was a grain crusher that would be efficient, inexpensive and would reduce the time required for crushing grains in comparison with a normally used mortar and pestle. The first step in the design process was an assessment of currently used grinding techniques.

There are three main methods used by most people in developing countries to crush grain ${ }^{7}$. The first is the use of a saddle stone or saddle quern. In this method a large stone is pushed forward and backward, away from and toward the user. This stone rides on top of a much larger base. The grain is placed on the base and the mobile stone passes over the grain repeatedly until the grain is pulverized to the desired coarseness. This is a very slow, painstaking, and highly labor intensive method of crushing grain. The second is the mortar and pestle. This method uses a stone bowl (mortar) containing the grain to be crushed and a shaft with a rounded stone or metal end (pestle) to pulverize the grain to the desired coarseness. The pestle is moved around in the mortar crushing the grain between the hard surfaces of the mortar and tip of the pestle. The longer the pestle or work in the mortar, the finer the grain gets crushed. Both of these methods require a great deal of upper body strength and muscular endurance. The final method is the rotary quern, or simply quern. This is similar to a continuous process than the saddle quern or mortar and pestle methods which are batch processes producing only small amounts at a time. The user loads grain to be crushed into a hole in the top of the upper stone which rotates above the lower stone which stays stationary. As the upper stone rotates, the grain loaded into the feed hole in the top works its way between the upper and lower stones. As more grain is fed between the stones the partially ground grain is pushed towards the outside of the stones where it can be collected. As the partially crushed grain works its way to the outside, it is crushed to a finer consistency along the way. This method uses the momentum of the rotating stone to help crush the grain, making it easier on the user to continue crushing for a longer period of time. This technique was used for many years on any number of scales from personal in home use to industrial sized mills powered by windmills to rotate the upper stone.

The rotary quern is the same principle used in many of the personal mills available today, with the difference that most of today's modern personal mills use shaped metal disks with an adjustable spacing to change how finely the grain is ground, in place of the traditional stone disks. These metal plates, shown in Figure 1, seemed to be the only way to effectively build a human powered grain crusher that would be more effective than the current systems in use.

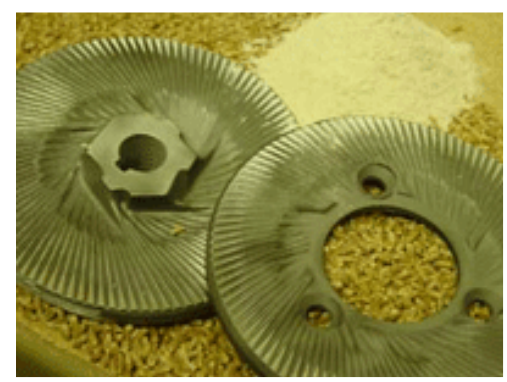

Figure 1: Modern shaped carbon steel grinding plates ${ }^{8}$.

\section{The Initial Design}

In developing a design there are many factors to consider. The main questions to consider are: who is the end user and what will the end user be doing with the device? The main end user for 
this device would be the people of developing countries and they would be using it to crush harvested grains into flour and various meals. Other considerations included local availability of materials, ability to be easily and locally produced, power and electricity usage and reliability, cost of building and maintenance, ergonomics, and local impact.

To address these requirements a search of existing designs revealed that there were only a few different types of personal crushing mills. The most common design is similar to the one shown in Figure 2 below available assembled or in parts from Country Living Grain Mills ${ }^{9}$.

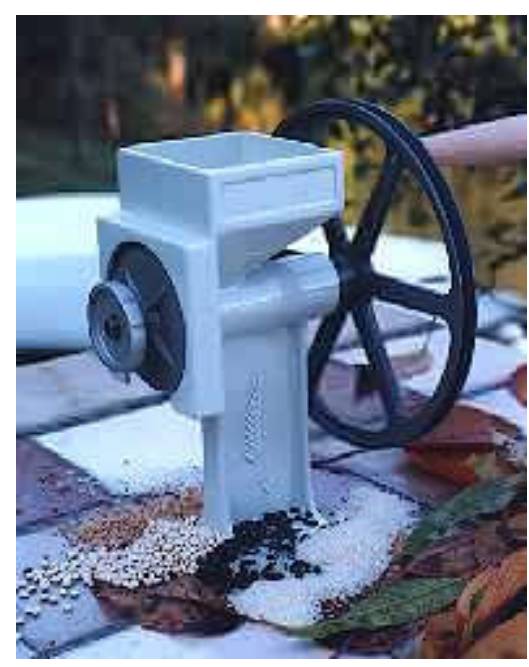

Figure 2: The most common type of personal grain mills 9 .

During the spring of 2007 semester, the goal was to design a grain crushing device that could be made at Rowan. To power the grain crusher, human energy would need to be converted to mechanical power for the grinder. Ideas generated included bicycles or stationary bicycles modified with a chain or belt drive to turn the Country Living Grain Crusher. The group decided that a bicycle stand for the existing bicycle would be the best idea for the scope of the project. A bicycle stand was constructed with intentions to be attached to a pre-existing grinder.

Special attention was paid to a wide range of adjustability so that the final product could fit a variety of bicycles. The stand would need to fit bikes with tire diameters ranging from 20 inches to 26 inches, and also with varying rear axle widths. The design also had to allow for tensioning of the drive belt, so it was decided that the grain crusher's location would be adjustable to provide such tension. The only fixed components would be the center drive axle and its supports. An overview of the previous design is shown below in Figure 3. Everything but the bolts and bearings is made of 6061 aluminum, because this is just a prototype. The rear bike wheel is held in place by two "pucks" with holes lathed into them so that it fits over the nut on the back axle. The support shafts that hold that puck are adjustable in height. The wheel rests on a roller once it is properly secured. The roller has 80 grit grip tape on it to ensure more friction. When the bike is pedaled, the roller turns a 3 inch v-belt pulley which is belted to a 12 inch pulley on the grain crusher itself. Slots are milled into the base so that the belt can be tensioned or replaced. An effort was also made to use as many off-the-shelf pieces as possible. This would limit machining time and product variability for the end-user. It was also proposed to include an electric motor 
that could be powered by solar energy. This would give users the option of human or electric power, so if they do not have electricity, they are still able to use the device.
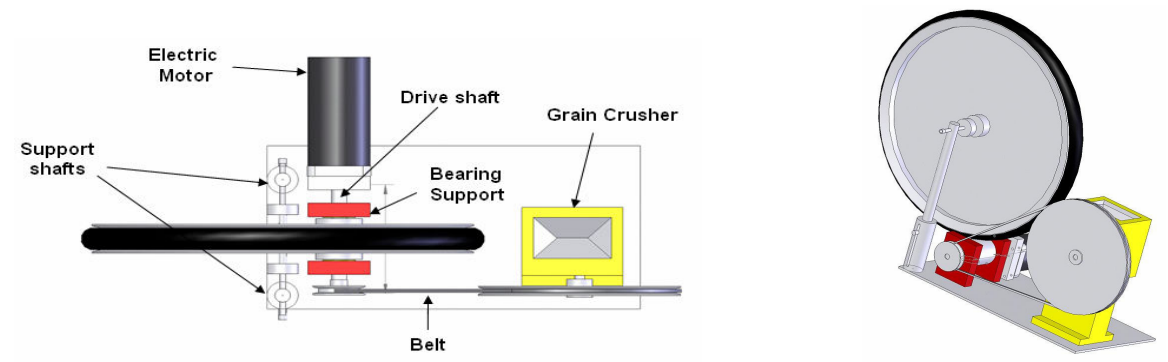

Figure 3: Initial design

During the Fall 2007 semester, the objective of this project returned to the original objective with a focus on reducing cost and weight of the product. In order to accomplish this, the Spring 07 design was turned into a working model and analyzed to determine how best to reduce the cost. It was found that if the team could create its own grain crusher instead of ordering a readymade grinder, the costs could be substantially reduced. This change also reduced the weight of the product because the crusher was made from aluminum instead of much heavier cast iron. The new crusher is designed to retro fit onto the previous base. One of the main sources of cost and weight is the electric motor. Although it is a great benefit to use solar power and electricity to grind the grain, it was later determined that the device is easy enough to use that an electric motor would not be necessary. It is the same width and roughly the same height. The method of grinding remains the same. The grain is fed in through the top of the grinder and is augured through a hole. That hole allows the grain to fall between two grinding plates. One plate is bolted down, and other rotates and the shear force grinds the grain. The whole assembly is shown in Figure 4 (bicycle excluded).

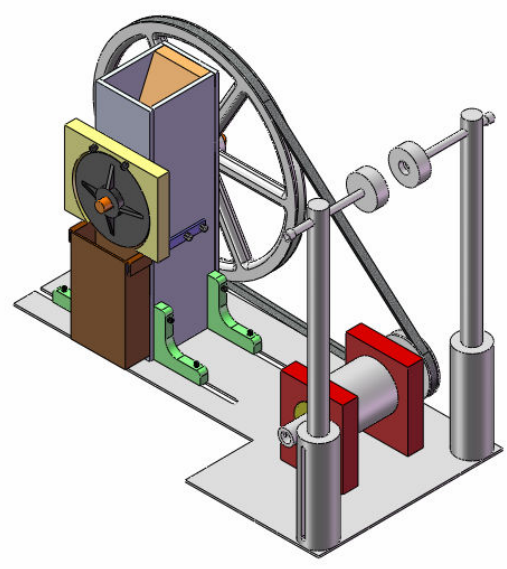

Figure 4: Fall 2007 Design

The Spring '07 design had a motor (\$225), Grain Crusher (\$375), and construction materials (\$200), so the cost of this design was approximately $\$ 800$ to build. For the Fall '07 design, the 
cost of the materials to make the crusher itself is approximately $\$ 224$, which shows that the objective of this project was reached. The new design costs $\$ 151$ less than the old one, excluding the motor. The motor was also eliminated from the design, saving more on the cost of the project. This would be one of the designs taken to India for the pilot study. These costs are based on cost of materials in the US and can be obtained much cheaper in developing countries.

Since a replicable design was available, the Rowan University Business Department showed interested in working with the project. After meeting with the group of business students to show them our drawings and explaining the concept of the project they decided to work on the marketing side of the project. At present, the business team is doing research on areas the finished project can be marketed in. They are also presenting to a group of possible entrepreneurs that might be interested in becoming involved in the project.

Another goal that was established was to provide visibility for the product being designed. To do this, a website was assembled to showcase the Grain Crusher project. It gives a brief background of the project as well as our current status ${ }^{10}$. It also gives links to the types of products used to create the grain crusher device. The site is currently up and running and has been updated recently with a photo gallery and video clip of the working model.

\section{Second Generation Design}

In the beginning of the Fall 2008 semester, it was decided that the grain crusher assembly should be made more reliable and user-friendly. An additional objective was to make the grain crusher cheaper and lighter and also sturdier by using steel. The new design still uses pedal power to turn the crusher, but it is self-contained so that you will not need to attach a bicycle. Steel is also less expensive than aluminum, but it is stronger so fewer support components will be needed. It is also chain driven instead of belt driven.

Another great benefit of this design is it reduced the cost of the crusher as well as the weight. The design has the same grinder plates and loading system as the Fall 2007 design, except an auger was added to increase the feed rate of the grain that is being ground up. The seat has 6 adjustable height levels. The gear ratio is slightly greater than $1: 1$, but is still relatively easy to pedal. Figure 5 shows the Fall 2008 design, which is the latest design without the funnel that is used to load the grain. 


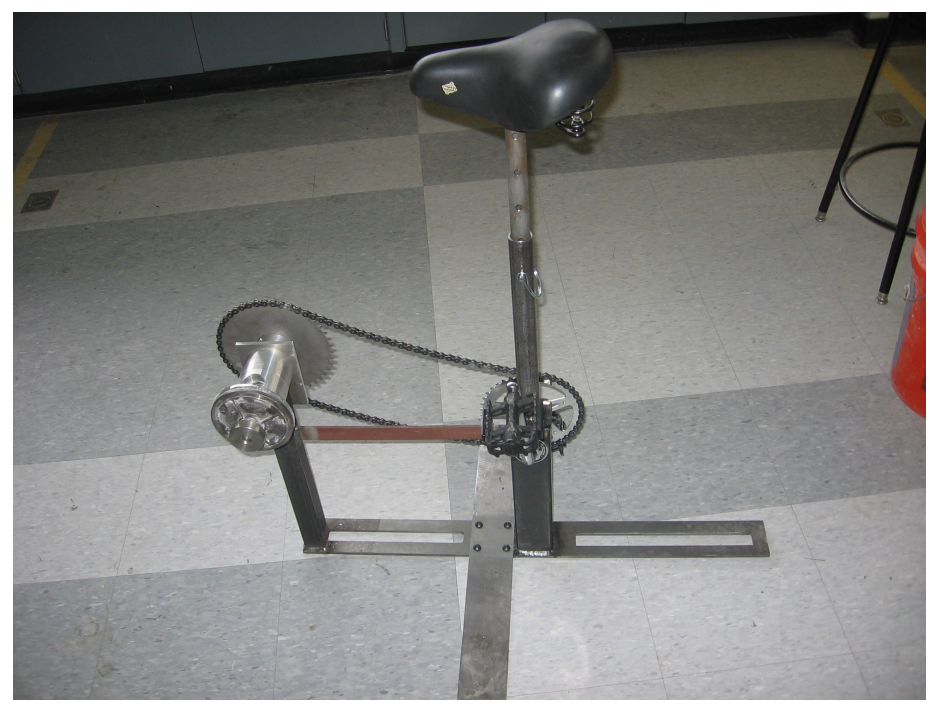

Figure 5: Fall 2008 design of the bike powered grain crusher excluding the funnel

\section{Pilot Study}

With two designs completed, preparation began for the pilot study. The pilot study was done in collaboration with Dhan Foundation ${ }^{11}$ in India. Sengalpaddai was the village in which the pilot study was conducted. The first part of the pilot study involved investigating the current methods used to grind grain. One aspect that was learnt during the process was that the villagers use a quern to "deshusk" lentils. Dehusking is the process in which the outer skin is removed and the lentil itself is broken in half. Once the people in the village separate the skin from the grain, it is ground up using a long stick and a bowl, a dry mortar and pestle, or a wet mortar and pestle (for flour).

The next step of the pilot study was to demonstrate how to use the Fall 2008 design. Once it was assembled, and a short demonstration was given, the end users in the village took turns using the crusher. This process was repeated for the Fall 2007 design. There were several major aspects that were observed. The first is that when adjusted properly, the crusher removed the skin of the lentils very well. Also, not many of the end users in the village wanted to sit on the seat and pedal, especially the women, because of the clothing that they customarily use, which would get tangled up in the chain. Instead, they preferred to sit behind the crusher and pedal by hand. Another noteworthy observation is that the Fall 2007 may be a little faster, but it is difficult to collect the crushed grain. Overall, the newer design was much better received than the older design.

Once the trial was done, a roundtable discussion was held to receive feedback and suggestions to improve the design. The suggestions including larger grinding plates to improve capacity and a faster spin rate to increase capacity. Another suggestion was to make one hand powered handle, instead of the foot pedals. They also wanted a better grain collection system.

The objective of the Spring 2009 semester was to make final improvements on the design and distribute the crusher where it is needed. Based on the suggestions of the villagers, changes to 
the design were made. Allowing the grain crusher to be powered by either the arms or the legs is the major revision in the design. The new design was made to make this change simple and quick. In this design, the user can attach the pedals and adjust the bike seat to the right height, allowing them to use their legs. If the user prefers arm power, they could attach the handles to the pedal arms and remove the bike seat. This would also allow them to mount the crusher to a table, or sit down behind the crusher. The new design with the handles is shown in Figure 6. Price is still a parameter, but since only the design drawings will be sent to India, size and weight is not a major concern. This is also only a guideline design for how to make a human powered grain crusher. The design can be changed to fit locally available materials. One example of this is the larger grinding plates. Madurai Mill Stores ${ }^{12}$ sells much larger grinding plates, and these are the plates that are available in the section of India in which the pilot study was conducted. The design of the hopper and feed line should be changed appropriately. Another aspect that should be taken into consideration is the gearing of the driveline. Any diameter ANSI 40 1/8 inch thick sprocket can be used, so the gearing can be adjusted to either be faster or easier on the end-user.

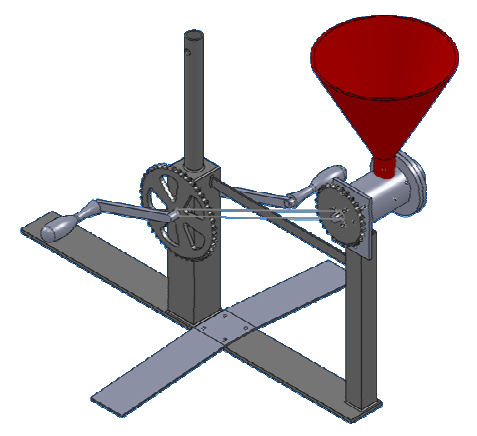

Figure 6: The latest design of the crusher based on feedback from the pilot study

This latest design is being manufactured and piloted in The Gambia as this paper is being drafted. The current project run through Engineers Without Borders at Rowan University is currently in The Gambia and as a result the prototype was sent there for pilot study and possible manufacturing. In addition, the design also won third place at the IEEE President's Change the World Competition $^{13}$.

The other device being developed presently based on an assessment of local needs is a Palm or Coconut tree climber.

\section{The Coconut Tree Climber}

\section{Introduction and Motivation}

Currently, a major global industry comes from coconut harvesting of farmed coconut trees as well as other palm tree nuts. To harvest coconuts and similar nuts, workers must climb to the top of the tree to reach the fruit. These climbers are free climbing up the tree barefoot with no safety 
gear to chop down coconuts. Due to the inherent danger of this act, the availability of climbers is decreasing due to injuries and deaths. In order to fix this issue, our team has proposed to create a device that will assist the tree climbers when harvesting coconuts.

The proposed tree climber is to provide safe travel up and down the tree as well as a stable platform while gathering coconuts at the top. The climbing device must be fast and efficient in order for the workers to adopt the new idea. Also, the device must be readily available or able to be built in remote areas in order to become a viable option for all tree climbing professionals. Safety must also be incorporated into the design to further limit any injuries or deaths. The design must be kept simple, yet effective for complete satisfaction.

\section{Constraints \& Criteria}

It is important to specify constraints and criteria on a project such as this. The main constraints of this device are the materials, methods used to construct the device and overall cost. The materials being utilized in the tree climber were selected specifically because of their availability and for the ease of construction. Steel tube, the main component, can be found in one form or another in most locations around the word. The construction methods used to build the tree climber are such that it can be built with locally available techniques. While tungsten inert gas (TIG) welding is being used for the prototypes, replications can be made using simple torch welding in underprivileged areas around the world. The cost of the device must be low as it is likely that individuals will be responsible for constructing their own personal tree climbing devices.

The main criteria for the tree climbing device will be its ability to enable quick climbing of trees, added safety, and ease of use of the device. The tree climbing device must be as efficient as the traditional method of climbing trees such that the production level of the harvesters cannot be decreased as a result of this device. The productivity is directly linked to the ease of use and the time it takes to climb the tree. Adding safety to tree climbing is a major criterion as this will allow harvesters to work more efficiently and common injuries can be avoided.

\section{Design}

Currently, a major global industry comes from coconut harvesting of farmed coconut trees as well as other palm tree nuts. To harvest coconuts and similar nuts, workers must climb to the top of the tree to reach the fruit. These climbers are free climbing up the tree barefoot with no safety gear to chop down coconuts. Due to the inherent danger of this act, the availability of climbers is decreasing due to injuries and deaths. In order to fix this issue, our team has proposed to create a device that will assist the tree climbers when harvesting coconuts.

The proposed tree climber is to provide safe travel up and down the tree as well as a stable platform while gathering coconuts at the top. The climbing device must be fast and efficient in order for the workers to adopt the new idea. Also, the device must be readily available or able to be built in remote areas in order to become a viable option for all tree climbing professionals. Safety must also be incorporated into the design to further limit any injuries or deaths. The design must be kept simple, yet effective for complete satisfaction. The initial design is shown in Figure 7. 


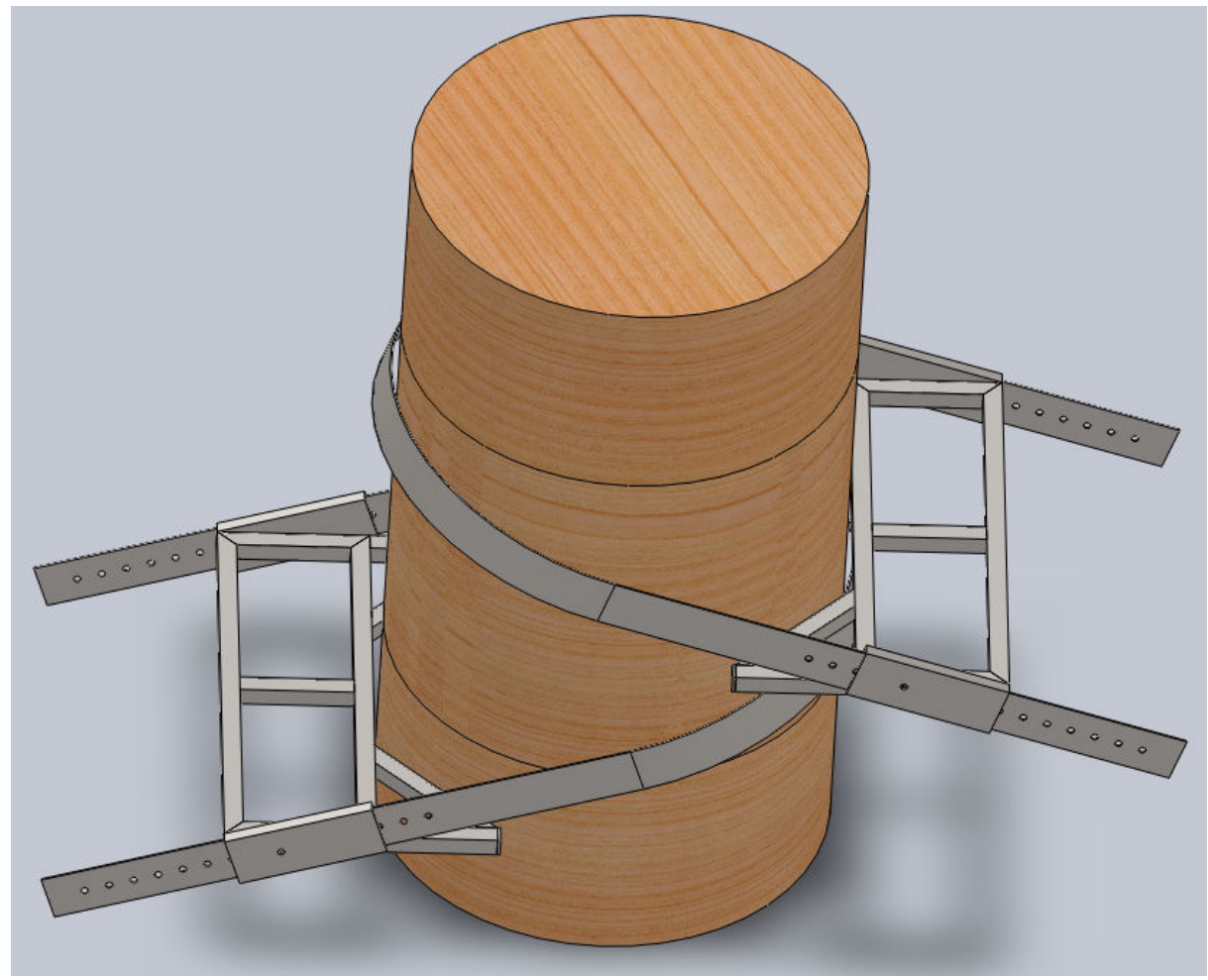

Figure 7: Initial two platform design.

After performing multiple test climbs, the initial design proved more difficult to use than expected. The device helped the climber travel up and down the tree, but required a certain level of control which was not possible through the initial design to make this design a viable climbing aid. The band design used limited the movement of the feet with respect to one another. The design required there to be a leading foot and a trailing foot. Due to the inherent band design, the two individual climbing aids would never be able to pass one another. This resulted in awkward and inefficient climbing. Another downfall to this design was how it is positioned around the tree; each individual foot was attached to the tree limiting the freedom for foot placement. This resulted in uncomfortable foot positioning causing an imbalance.

After the design was rendered in a CAD program a finite element stress analysis was performed. The stress analysis was simulated as a single point load at the center of the outer bar with a load twice what was expected to be dispersed over the entire platform. The load applied for the simulation was 300 pounds. The result of the simulation is shown in Figure 8. The image shows a large exaggeration of the actual deflection but it can be seen that the maximum stress is well below the yield strength of the material. This worst case scenario showed that the device was well within a safe range of operation for the weight of a person. 


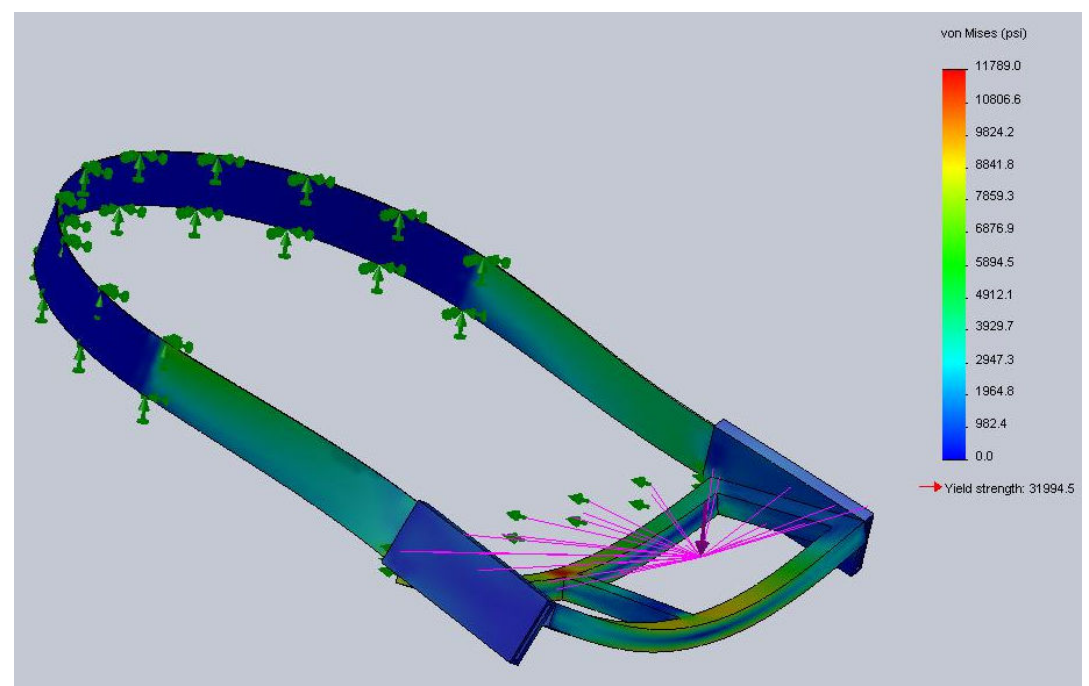

Figure 8: Result of the stress analysis showing a large exaggeration of the actual deflection due to loading in a "worst case scenario".

It was concluded that the design could be used to climb a tree, but very inefficiently. The proposed tree climber must be as fast if not faster than the current climbing methods and provide more safety for acceptance and implementation. Therefore, the team revised the initial design and came up with a new model.

\section{Second Design}

With the results and observations from the testing of the initial design, the team has redesigned the tree climbing device. The new design has one platform for the user's feet rather than two, as seen in Figure 9. This design is much more like tree stands found in use by hunters; however it differs in some key categories. Tree stands available to consumers range in price from $\$ 200$ to $\$ 400$, this design will be built with materials costing less than $\$ 100$. This device will be smaller and lighter than available tree-stands which are beneficial because the time spent in the tree will be less than five minutes and it will be carried from tree to tree many times a day. It also has a hand device to aid in climbing, as seen in Figure 10.

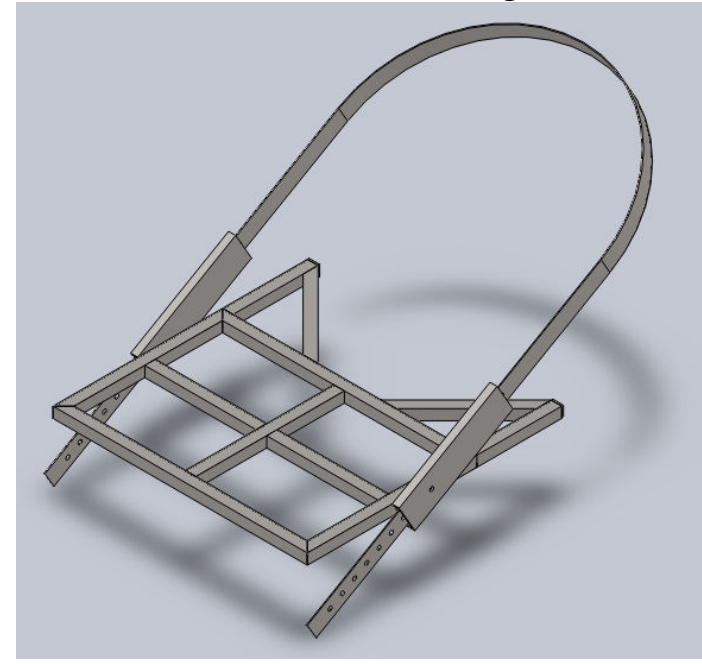

Figure 9: Revised design.

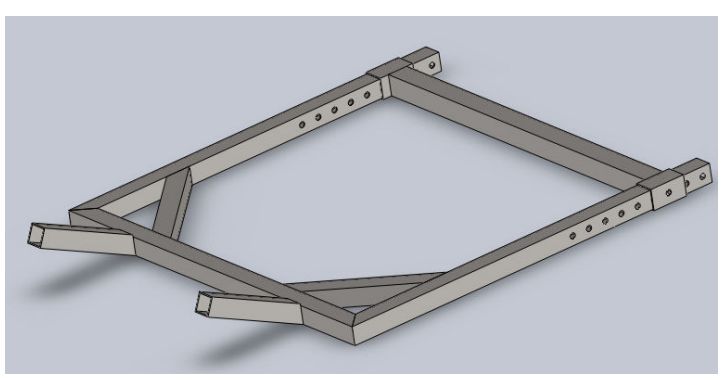

Figure 10: Climbing Hand Aid 
Essentially, the base platform utilizes a cantilever design were the force exerted on the tree is horizontal and vertical shear is limited. As the bottom base is raised, the platform angles in toward the tree which increases the effective radius of the band. In doing so, the base can be raised up by your feet and move it up the tree. Once pressure is applied to the base, it levels out and the band allows the cantilever effect to take place. This provides extreme stability and control when climbing. In order to assist the climber, a climbing hand aid was also implemented. Because this design utilized a single platform, a climbing hand aid was needed to raise your legs up the tree. Basically, the climbing aid is placed above your head and used to pull your body up. Once your body is pulled up, pressure is applied to the base and the climbing aid is released and raised up. This process is repeated for safe passage up and down the tree. The new design will be revised and finalized in the following weeks. An end of semester design decision was made to alter the current design. The team decided that instead of building a model that is already slimmed down, they would build an optimal model, neglecting price and material constraints, to optimize function. Once the function, which is climbing up and down a tree, is optimized, it will them be slimmed down to fit within the criteria and constraints provided. It will then be built as a prototype and tested on campus at Rowan University by the design team. Once the team is satisfied with the design, the prototype will be taken to coconut farms for testing. Input and observations from tree climbing professionals will be considered in further designs to make the best device possible.

\title{
Conclusion
}

The project described here shows a feasible option to integrate Service Learning with Engineering design. Designing devices for developing countries is a critical component of these projects and exposes students to Principles of Development of Appropriate and Sustainable Technologies. The redesign of the device to control costs and with end-user feedback is a valuable lesson for students, which cannot be taught in traditional engineering classes but through such Experiential Learning courses. The benefits to students include learning the design process, learning about traditions and constraints in developing countries, developing devices that will be beneficial to a large number of end users, and the joy derived from lending a helping hand to people around the globe.

\author{
Bibliography \\ ${ }^{1}$ Dewey, J. Experience and Education, NY, Collier, 1938 \\ ${ }^{2}$ Weil, S. and McGill, I. A Framework for Making Sense of Experiential Learning In S. Weil and I. Mc Gill (Ed.) \\ Making sense of Experiential Learning (pp. 3-24). Guildford, England: Society for Research Into Higher Education \\ and Open UP, 1989 \\ ${ }^{3}$ Westheimer, J., Kahne, J. and Gerstein A. School Reform for the Nineties: Opportunities and Obstacles for \\ Experiential Educators, The Journal of Experiential Education Vol. 15, No. 2, (1992), pp. 44-49.
}


${ }^{4}$ Beena Sukumaran, Kauser Jahan, Dianne Dorland, Jess Everett, Jennifer Kadlowec, Zenaida Gephardt, and Steven Chin, "Engineering Clinics: An integration of research into the undergraduate engineering curriculum," CUR quarterly, Vol. 26, No. 3, (2006), pp. 115-121

${ }^{5}$ James Newell, Anthony Marchese, Ravi Ramachandran, Beena Sukumaran, Roberta Harvey, "Multi-disciplinary design and communication: a pedagogical vision," International Journal of Engineering Education. Vol. 15 (1999), pp. 376-382.

${ }^{6}$ Mehta, Y., and Sukumaran, B. (2007), “Integrating Service Learning in Engineering Clinics,” International Journal for Service learning in Engineering, Vol. 2, No. 1,(2007), pp. 32-43.

${ }^{7}$ Teague, Walter Dorwin. Flour for Man's Bread: A History of Milling. University of Minnesota Press. 1952.

${ }^{8}$ Image of metal grinding plates used in grinding mills, Accessed on January 5, 2010 from http://countrylivinggrainmills.com/store/parts/grindingPlates.jpg

${ }^{9}$ Image of Country Living Grinding Mill, Accessed on January 5, 2010 from http://countrylivinggrainmills.com/store/mill/mill.jpg

${ }^{10}$ Engineering Innovators without Borders webpage, http://users.rowan.edu/ poslus28/My\%20Web\%20Sites/Grain\%20Crusher/EIWB\%20Home.htm

${ }^{11}$ Dhan Foundation website, http://www.dhan.org, Accessed January 6, 2010.

${ }^{12}$ Madurai Mill Stores, http://www.maduraimillstores.com, Accessed January 20, 2009.

${ }^{13}$ Announcement of the IEEE President's Inaugural Change the World Competiton, Accessed on January 6, 2010 from http://www.ieee125.org/files/IEEE\%20Presidents\%20Competition\%20Flyer\%20FINAL.pdf. 